\title{
Ghrelin and oral diseases
}

\author{
SYLWIA MAEGORZATA SEOTWIŃSKA
}

Department of Oral Hygiene, Medical University of Warsaw, Poland

\begin{abstract}
Eating food is one of the most complicated behaviours in mammals, especially humans. The primary function of ghrelin is regulation of the appetite level and its stimulation. It is also responsible for the body's energy balance and glucose homeostasis. Ghrelin has been shown to affect many brain structures, which confirms the presence of ghrelin receptors in the brain. Studies are also conducted to assess the possible role of ghrelin in anxiety states and in memory disorders and motor dysfunctions. Ghrelin has been found in saliva and salivary glands, teeth and gums, and in the taste buds of the tongue epithelium; it is also secreted by mucosal cells and gingival fibroblasts. The presence of ghrelin in developmental enamel, especially in odontoblasts and ameloblasts, may suggest its regulatory role in the development of teeth. Patients with chronic periodontitis have significantly higher concentrations of ghrelin in the peripheral blood serum, as compared to the control group. Ghrelin plays a special role in the proliferation of cancer cells and in the development of neoplastic metastases. The abundant presence of ghrelin receptors in cancer cells is considered an important target in the treatment of neoplasms. Ghrelin is a hormone whose multidirectional mechanism of action has not yet been fully understood. However, its ubiquitous occurrence in the human body and its very diverse participation in metabolic processes may prove to be a significant obstacle in achieving the expected clinical effect of ghrelin as an effective drug in selected disease units.
\end{abstract}

Key words: ghrelin, salivary secretion, oral diseases, oral cancer, healing.

(Cent Eur J Immunol 2020; 45 (4): 433-438)

Eating food is one of the most complicated behaviours in mammals, especially humans. It is modulated and controlled by a number of endogenous and exogenous factors. One of the key compounds regulating this process is ghrelin, a natural peptide hormone consisting of a chain of 28 amino acids. It occurs in all vertebrates, including fish, amphibians and mammals and in the human body. Ghrelin is produced mainly in the stomach by the parietal cells of the mucous membrane, which is the main source of endogenous ghrelin. Ghrelin was first identified in the stomachs of rats, as an endogenous ligand for the receptor releasing the growth hormone $(\mathrm{GH})[1,2]$. The primary function of ghrelin is regulation of the appetite level and its stimulation. Ghrelin is not secreted into the gastrointestinal tract; instead it enters the blood vessels and is distributed throughout the body with blood. It is synthesized and secreted in the stomach, by endocrine X/A type cells. It is also secreted in smaller quantities in the smaller intestine, the pancreas and many other organs, such as kidneys, placenta, thyroid, pituitary gland and hypothalamus [1, 3, 4]. Ghrelin immunoactive cells have been found both in the small intestine and in the large intestine [3]. Ghrelin is also produced by cells of the central nervous system, but in much smaller amounts, as compared to gastric enteroendocrine cells [1]. It is commonly called the hunger hor- mone. It is also responsible for the body's energy balance and glucose homeostasis [5]. In experimental animals, the level of ghrelin in the blood serum increases significantly during fasting and decreases after feeding or introduction directly into the stomach. Experimental administration of exogenous ghrelin to rodents causes a rapid increase in appetite and increased food intake, with a significant weight gain [6-8].

The production of ghrelin in the body of healthy people is inseparably connected with the eating process, and the amount of ghrelin in saliva increases during eating. When a body is starved for a long time, ghrelin is released, causing the feeling of hunger and the craving for food. Ghrelin levels decrease as a result of satisfying hunger and the effect of fullness. Daily fluctuations are observed in the case of concentration of this hormone in blood, with an increase before meals, and a sharp decrease after meals [8, 9]. This means that ghrelin is a key regulator of the initiation of eating activities, stimulating the cascade of events preparing the body for the upcoming meal. Ghrelin levels also rise during fasting and during sleep between 10 p.m. and 4 a.m., and decrease for about an hour or two after a meal. Sleep deprivation increases ghrelin levels, therefore increasing the risk of gaining weight. People with severe obesity and those with eating disorders, such as bulimia or

Correspondence: Sylwia Małgorzata Słotwińska, Department of Oral Hygiene, Medical University of Warsaw, 6 Stanislawa Binieckiego St., 02-097 Warsaw, Poland, e-mail: sylwia.slotwinska@wum.edu.pl

Submitted: 4.10.2020; Accepted: 22.10.2020

This is an Open Access article distributed under the terms of the Creative Commons Attribution-NonCommercial-ShareAlike 4.0 International (CC BY-NC-SA 4.0). License (http://creativecommons.org/licenses/by-nc-sa/4.0/) 
anorexia, have consistently high levels of ghrelin, which means they feel hunger regardless of their actual need for food. Ghrelin has very diverse control and modulation effects throughout the body [10]. Its regulatory role is emphasized, both in the central nervous system, especially in the brain, and in peripheral nerves. In experimental studies and clinical observations, ghrelin has been shown to affect many brain structures, which confirms the presence of ghrelin receptors in the brain. Goldstein et al. demonstrated that ghrelin-stimulated secretion of GH in the pituitary gland is critical for protecting the body against hypoglycaemia caused by prolonged fasting [11], which is also associated with weight regulation by increasing body fat and, consequently, reducing energy expenditure [12, 13]. It has also been shown that ghrelin is involved in centrally regulated processes of learning, rewarding, stimulating mood and memory, and in response to stress [8, 14, 15]. However, its peripheral effects include gastrointestinal motility, functioning of the immune system, glucose homeostasis and bone formation [5, 16-21]. Ghrelin was also found in heart cells, which may suggest both its cardiovascular effects and cardioprotective properties. Its protective effect on rodent cardiomyocytes has been described [20, $22,23]$. Studies are also conducted to assess the possible role of ghrelin in anxiety states and in memory disorders and motor dysfunctions [8].

In the light of the observations so far, ghrelin has become the subject of studies evaluating its usefulness in the treatment of many diseases, in particular metabolic syndromes. Shiomi et al. demonstrated the effectiveness of Z-505 (ghrelin receptor agonist) in the treatment of anorexia after total gastrectomy in an animal model [24]. Drugs that block ghrelin receptors are believed to be useful in the treatment of eating and appetite disorders, especially in the treatment of obesity and anorexia. The development of effective anti-obesity therapy has become a priority in the context of the increase in the global incidence of this disease. According to the World Health Organization, there are currently over 2 billion adults worldwide who are overweight, and nearly 700 million are morbidly obese. Despite modern public health education campaigns, obesity is reaching the proportions of a serious social pandemic, an ever-increasing health problem that remains unsolved in modern society. This situation provides an important impetus to study the mechanisms underlying central appetite regulation with the aim of developing novel strategies for treating eating disorders. Literature on ghrelin contains a great deal of information regarding the role of this hormone in a wide variety of physiological processes. Therefore, many attempts have been made to use ghrelin in pharmacotherapy. However, more than 20 years after the discovery of ghrelin by Kojima and his colleagues, no effective anti-obesity drug related to ghrelin has been introduced into clinical practice; nor have any therapies to treat chronic starvation and cachexia based on knowl- edge of ghrelin been developed. It seems that the basic problem is the very frequent presence in the human body of the GHSR-1a receptor for ghrelin, which, apart from its typical location in the gastrointestinal tract, is also located in the cells of the pancreas, spleen, myocardium, bones, adipose tissue, thyroid gland, adrenal glands and in the vagus nerve afferents and cells of the immune system $[1-4,25,26]$. Due to the ubiquitous expression of the GHSR-1a receptor, administration of exogenous ghrelin or ghrelin ligand may lead to a cascade of uncontrolled and unintended physiological and pathological reactions. Thus, therapeutic administration of exogenous ghrelin or its derivatives not only does not guarantee effective control of food consumption and selective appetite modulation, but also results in exerting a significant effect on many other central and peripheral processes, which can significantly disturb the complex metabolic balance and homeostasis of the body [27-30]. Moreover, ghrelin plays a key role in central regulation by contributing to the functioning of the hypothalamic-pituitary-adrenal axis. The results of studies suggest that ghrelin acts both peripherally, modulating the function of the gastrointestinal tract via the vagus nerve, and by redistributing the ghrelin GHSR-1a receptor in the gastrointestinal tract, which paves the way for local activity [6-9, 31]. In selected situations, central and peripheral ghrelinergic signalling seem to be complementary, as is the case of glucose homeostasis and visceral pain, as well as gastrointestinal motility regulation, including ghrelin receptors located in the oral cavity [6-9, 14, 23-26, 32].

In the mouth, ghrelin was found in saliva and salivary glands, teeth and gums, and in the taste buds of the tongue epithelium; it is also secreted by mucosal cells and gingival fibroblasts [33-38]. The presence of ghrelin in developmental enamel, especially in odontoblasts and ameloblasts, may suggest its regulatory role in the development of teeth [35]. The concentration of ghrelin in saliva is comparable to the concentration of ghrelin in the peripheral blood serum and in the plasma, which may suggest its effect on the development and course of diseases of the oral cavity $[37,38]$.

It has been shown that stressful situations, especially in patients suffering from bulimia nervosa $(\mathrm{BN})$, increase the concentration of ghrelin in saliva [38, 39]. It has been proven that ghrelin significantly reduces the expression of proinflammatory cytokines, which may have an important impact on diseases with inflammatory reactions and the body's response in the process of tissue healing [16, 40]. Warzecha et al. investigated the effect of ghrelin administration on the healing of oral ulcers in rats. Treatment with ghrelin accelerated the healing of oral ulcers in rats with intact salivary glands and in rats with decreased salivary production due to removal of the salivary glands. Increases in blood flow and in cell proliferation in the mucosa were achieved, as well as a decrease in local inflammation in conjunction with a significant decrease in the 
concentration of pro-inflammatory interleukin $1 \beta$ (IL-1 $\beta$ ) in the mucous membrane [41]. Similar results were obtained by administering exogenous ghrelin preparation to rats with gingival ulcerations for 6 days [42]. In both of these experiments, ghrelin acted as an inhibitor of the inflammatory reaction, in which IL- $1 \beta$ always plays a key role, being a well-known mediator of acute inflammation and the body's systemic immune response, and a catalyst for the release of a cascade of other pro-inflammatory cytokines. IL-1 $\beta$ stimulates the production and release of further inflammatory mediators, such as tumour necrosis factor, platelet activating factor, prostaglandins and other pro-inflammatory interleukins [43]. Administration of the IL-1 receptor antagonist has been shown to slow down and ameliorate the systemic inflammatory response [44-46].

Many immunocompetent cells contain ghrelin receptors $[47,48]$. The effect of ghrelin on the immune system is multidirectional and includes the alleviation of septic shock [49], the promotion of thymopoiesis in the course of aging [50], the inhibition of the phagocytic activity of macrophages [51] and blocking the expression of pro-inflammatory cytokines [16]. The local inflammatory response, which can induce uncontrolled production of pro-inflammatory cytokines, is characteristic of chronic periodontitis, a disease involving gradual destruction of the apparatus supporting the tooth in the alveolus, loss of connective tissue attachment, damage to bone structures and the formation of deep periodontal pockets, populated by periopathogenic microorganisms with a high degree of virulence. The cells that play the most important role in defence against microorganisms are the neutrophilic granulocytes. Ghrelin is one of the important mediators in the innate immune response regulated by neutrophils [16, 40]. Local inflammation such as chronic periodontitis has a huge impact on the overall health of the body. The relationship of periodontitis with many systemic and chronic diseases was proven, especially with type 2 diabetes, in the course of which low concentrations of ghrelin in peripheral blood serum were detected $[52,53]$. However, when diabetes is accompanied by periodontitis, we often observe increased concentrations of ghrelin in plasma and peripheral blood serum, as compared to the control groups [54]. The level of ghrelin in the gingival pocket fluid and other biomarkers associated with diabetes increases significantly $[40,54,55]$. It is believed that the observed tendency to increased ghrelin concentrations in many patients with type 2 diabetes is caused by the synergy effect of chronic periodontitis and type 2 diabetes [54]. Patients with chronic periodontitis have significantly higher concentrations of ghrelin in the peripheral blood serum, as compared to the control group [55]. High concentrations of ghrelin are also found in many chronic inflammatory conditions, such as Leśniowski-Crohn disease and inflammatory bowel disease [56].

Very interesting studies concern the role of ghrelin in the process of angiogenesis. The results of these studies are inconclusive. Ghrelin has been shown to stimulate the formation of new capillaries in rat myocardium [57]. In contrast, other authors found that ghrelin inhibits in vitro angiogenic activity of brain cells [58]. The gradual inhibition of the angiogenesis process, progressing with age, is the result of ghrelin deficiency, caused by physiological changes occurring in the body aging process [59]. In turn, excessive angiogenesis is one of the elements of the pathogenesis of periodontitis. Already in the 1990s, it was demonstrated that the concentration of one of the angiogenic factors - vascular endothelial growth factor in saliva and gingival fluid - in people with periodontitis is higher than in the group of people with clinically healthy periodontium $(p<0.05)$, and correlates with the clinical periodontal condition $[60,61]$.

The relationship of decreased ghrelin concentrations with pathological conditions occurring in the oral cavity, such as changes in the mucous membrane, dental, gum and periodontal diseases, as well as abnormalities in the composition and secretion of saliva in the course of eating disorders, mainly in anorexia nervosa and $\mathrm{BN}$, has been the subject of studies for many years. Patients with these diseases display low bone mass combined with ossification disorders, frequently including advanced osteoporosis, as well as mucosal atrophy and dental erosion, and frequent swelling of the salivary glands with accompanying pain [62-69]. The analysis of the aetiology and pathophysiology of eating disorders indicates that the dysregulation of the network controlling the processes related to the eating function causes aberrations in eating habits and may contribute to the development of many other diseases. Ghrelin, as mentioned earlier, increases the appetite because its active form, acylated ghrelin, may cross the blood-brain barrier and thus activate neurons that increase appetite [70-73].

Oral ghrelin comes primarily from the salivary glands, where it is produced. Saliva production is controlled by the sympathetic and parasympathetic autonomic nervous systems. Thus, the central regulation of saliva production by the neural network may affect the production of ghrelin in saliva [74]. Based on many years of studies and observation, Ohta et al. argued that oral ghrelin is one of the important regulatory factors of the innate immune response to inflammation [75]. Reports of a relationship between ghrelin and periodontitis are contradictory. A positive correlation of blood concentrations $(r=0.708 ; p<0.05)$ was demonstrated between ghrelin and IL-1 $\beta$ in experimental periodontitis in female rats, but only in the postmenopausal period [76].

Nokhbehsaim et al. demonstrated the important role of Fusobacterium nucleatum - bacteria causally associated with periodontitis - and IL-1 $\beta$ in the modulation of ghrelin GHS-R1a receptor expression in the course of periodontitis [77-79].

There are numerous reports indicating the participation of ghrelin in the pathogenesis of many neoplastic diseas- 
es [80-84]. Ghrelin is believed to play a special role in the proliferation of cancer cells and in the development of neoplastic metastases $[85,86]$. Ghrelin receptors have been discovered in oral cancer [87]. The assessment of serum ghrelin concentration and the degree of ghrelin receptors' expression in tissues may aid in the diagnosis and differentiation of oral cancers [87-89]. The numerous presence of ghrelin receptors in cancer cells is considered an important target in the treatment of neoplasms [89].

Ghrelin is a hormone whose multidirectional mechanism of action is not yet fully understood. For years, experimental studies on the diagnostic and therapeutic use of ghrelin have been carried out [90]. However, its ubiquitous occurrence in the human body and its very diverse participation in metabolic processes may prove to be a significant obstacle in achieving the expected clinical effect of ghrelin as an effective drug in selected disease units.

\section{The author declares no conflict of interest.}

\section{References}

1. Kojima M, Hosoda H, Date Y, et al. (1999): Ghrelin is a growth-hormone-releasing acylated peptide from stomach. Nature 402: 656-660.

2. Hosoda H, Kojima M, Matsuo H, et al. (2000): Ghrelin and des-acyl ghrelin: two major forms of rat ghrelin peptide in gastrointestinal tissue. Biochem Biophys Res Commun 279: 909-913.

3. Date Y, Kojima M, Hosoda H, et al. (2000): Ghrelin, a novel growth hormone-releasing acylated peptide, is synthesized in a distinct endocrine cell type in the gastrointestinal tracts of rats and humans. Endocrinology 141: 4255-4261.

4. Kanamoto N, Akamizu T, Hosoda H, et al. (2001): Substantial production of ghrelin by a human medullary thyroid carcinoma cell line. J Clin Endocrinol Metab 86: 4984-4990.

5. Alamri BN, Shin K, Chappe V, et al. (2016): The role of ghrelin in the regulation of glucose homeostasis. Horm Mol Biol Clin Investig 26: 3-11.

6. Asakawa A, Inui A, Kaga T, et al. (2001): Ghrelin is an appetite-stimulatory signal from stomach with structural resemblance to motilin. Gastroenterology 120: 337-345.

7. Nakazato M, Murakami N, Date Y, et al. (2001): A role for ghrelin in the central regulation of feeding. Nature 409: 194198.

8. Carlini VP, Monzon ME, Varas MM, et al. (2002): Ghrelin increases anxiety-like behavior and memory retention in rats. Biochem Biophys Res Commun 299: 739-743.

9. Cummings DE, Purnell JQ, Frayo RS, et al. (2001): A preprandial rise in plasma ghrelin levels suggests a role in meal initiation in humans. Diabetes 50: 1714-1719.

10. Smith RG (2016): Dissociating ghrelin-dependent G protein from beta-arrestin-2 signaling in transgenic rats. Sci Signal 9: 424.

11. Goldstein JL, Zhao TJ, Li R, et al. (2011): Surviving starvation: essential role of the ghrelin-growth hormone axis. Cold Spring Harb Symp Quant Biol 76: 121-127.

12. Tschop M, Smiley DL, Heiman ML (2000): Ghrelin induces adiposity in rodents. Nature 407: 908-913.
13. Takaya K, Ariyasu H, Kanamoto N, et al. ( 2000): Ghrelin strongly stimulates growth hormone release in humans. J Clin Endocrinol Metab 85: 4908-4911.

14. Abizaid A, Liu ZW, Andrews ZB, et al. (2006): Ghrelin modulates the activity and synaptic input organization of midbrain dopamine neurons while promoting appetite. J Clin Investig 116: 3229-3239.

15. Chuang JC, Perello M, Sakata I, et al. (2011): Ghrelin mediates stress-induced food-reward behavior in mice. J Clin Investig 121: 2684-2692.

16. Dixit VD, Schaffer EM, Pyle RS, et al. (2004): Ghrelin inhibits leptin- and activation-induced proinflammatory cytokine expression by human monocytes and $\mathrm{t}$ cells. J Clin Investig 114: 57-66.

17. Sato T, Fukue Y, Teranishi H, et al. (2005): Molecular forms of hypothalamic ghrelin and its regulation by fasting and 2-deoxyd-glucose administration. Endocrinology 146: 2510-2516.

18. Chen J, Liu X, Shu Q, et al. (2008): Ghrelin attenuates lipopolysaccharide-induced acute lung injury through NO pathway. Med Sci Monit Int Med J Exp Clin Res 14: Br141Br146.

19. Li G, Li J, Zhou Q, et al. (2010): Growth hormone releasing peptide-2, a ghrelin agonist, attenuates lipopolysaccharide-induced acute lung injury in rats. Tohoku J Exp Med 222: 7-13.

20. Baldanzi G, Filigheddu N, Cutrupi S, et al. (2002): Ghrelin and des-acyl ghrelin inhibit cell death in cardiomyocytes and endothelial cells through ERK1/2 and PI 3-kinase/AKT. J Cell Biol 159: 1029-1037.

21. Muccioli G, Lorenzi T, Lorenzi M, et al. (2011): Beyond the metabolic role of ghrelin: a new player in the regulation of reproductive function. Peptides 32: 2514-2521.

22. Ozbay Y, Aydin S, Dagli AF, et al. (2008): Obestatin is present in saliva: alterations in obestatin and ghrelin levels of saliva and serum in ischemic heart disease. BMB Reports 41 : 55-61.

23. Kojima M, Hosoda H, Matsuo H, et al. (2001): Ghrelin: discovery of the natural endogenous ligand for the growth hormone secretagogue receptor. Trends Endocrinol Metab 12: 118-122.

24. Shiomi Y, Yoshimura M, Hori Y, et al. (2020): Z-505, an oral ghrelin receptor agonist, attenuates anorexia after total gastrectomy in rats. J Surg Res 246: 527-534.

25. Gnanapavan S, Kola B, Bustin SA, et al. (2002): The tissue distribution of the mRNA of ghrelin and subtypes of its receptor, GHS-R, in humans. J Clin Endocrinol Metab 87: 29882991.

26. Stengel A, Goebel M, Wang L, et al. (2010): Ghrelin, des-acyl ghrelin and nesfatin-1 in gastric X/A-like cells: Role as regulators of food intake and body weight. Peptides 31: 357-369.

27. Wren AM, Small CJ, Abbott CR, et al. (2001): Ghrelin causes hyperphagia and obesity in rats. Diabetes 50: 2540-2547.

28. Horvath TL, Castaneda T, Tang-Christensen M, et al. (2003): Ghrelin as a potential anti-obesity target. Curr Pharm Des 9: 1383-1395.

29. Lavin JH, Wittert G, Sun WM, et al. (1996): Appetite regulation by carbohydrate: role of blood glucose and gastrointestinal hormones. Am J Physiol 271: 209-214.

30. Flint A, Gregersen NT, Gluud LL, et al. (2007): Associations between postprandial insulin and blood glucose responses, appetite sensations and energy intake in normal weight and overweight individuals: a meta-analysis of test meal studies. Br J Nutr 98: 17-25. 
31. Fujino K, Inui A, Asakawa A, et al. (2003): Ghrelin induces fasted motor activity of the gastrointestinal tract in conscious fed rats. J Physiol 550: 227-240.

32. Shintani M, Ogawa Y, Ebihara K, et al. (2001): Ghrelin, an endogenous growth hormone secretagogue, is a novel orexigenic peptide that antagonizes leptin action through the activation of hypothalamic neuropeptide $\mathrm{Y} / \mathrm{Y} 1$ receptor pathway. Diabetes 50: 227-232.

33. Li BB, Chen ZB, Li BC, et al. (2011): Expression of ghrelin in human salivary glands and its levels in saliva and serum in Chinese obese children and adolescents. Arch Oral Biol 56: 389-394.

34. Aydin S, Ozercan IH, Geckil H, et al. (2007): Ghrelin is present in teeth. J Biochem Mol Biol 40: 368-372.

35. Liu B, Han X, Feng W, et al. (2016): Altered distribution of Ghrelin protein in mice molar development. Arch Oral Biol 65: 82-86.

36. Shin YK, Martin B, Kim W, et al. (2010): Ghrelin is produced in taste cells and ghrelin receptor null mice show reduced taste responsivity to salty $(\mathrm{NaCl})$ and sour (citric acid) tastants. PLoS One 5: e12729].

37. Groschl M, Topf HG, Bohlender J, et al. (2005): Identification of ghrelin in human saliva: production by the salivary glands and potential role in proliferation of oral keratinocytes. Clin Chem 51: 997-1006.

38. Dynesen AW, Bardow A, Astrup A, et al. (2008): Mealinduced compositional changes in blood and saliva in persons with bulimia nervosa. Am J Clin Nutr 87: 12-22.

39. 39. Monteleone P, Tortorella A, Scognamiglio P, et al. (2012): The acute salivary ghrelin response to a psychosocial stress is enhanced in symptomatic patients with bulimia nervosa: a pilot study. Neuropsychobiology 66: 230-236.

40. Ohta K, Laborde NJ, Kajiya M, et al. (2011): Expression and possible immune-regulatory function of ghrelin in oral epithelium. J Dental Res 90: 1286-1292.

41. Warzecha Z, Kownacki P, Ceranowicz P, et al. (2013): Ghrelin accelerates the healing of oral ulcers in non-sialoadenectomized and sialoadenectomized rats. J Physiol Pharmacol 64: 657-668.

42. Cieszkowski J, Warzecha Z, Ceranowicz P, et al. (2017): Therapeutic effect of exogenous ghrelin in the healing of gingival ulcer is mediated by the release of endogenous growth hormone and insulin-like factor-1. J Physiol Pharmacol 68: 609-617.

43. Dinarello CA, Simon A, van der Meer JW (2012): Treating inflammation by blocking interleukin-1 in a broad spectrum of diseases. Nat Rev Drug Discov 11: 633-652.

44. De Koning HD, Schalkwijk J, van der Ven-Jongekrijg J, et al. (2012): Sustained efficacy of the monoclonal anti-interleukin-1beta antibody canakinumab in a 9-month trial in Schnitzler's syndrome. Ann Rheum Dis 72: 1634-1638.

45. Dinarello CA (2011): A clinical perspective of IL-1beta as the gatekeeper of inflammation. Eur J Immunol 41: 1203-1217.

46. Herlin T, Fiirgaard B, Bjerre M, et al. (2013): Efficacy of anti-IL-1 treatment in Majeed syndrome. Ann Rheum Dis 72:410-413.

47. Hattori N, Saito T, Yagyu T, et al. (2001): GH, GH receptor, $\mathrm{GH}$ secretagogue receptor, and ghrelin expression in human T cells, B cells, and neutrophils. J Clin Endocrinol Metab 86: 4284-4291.

48. Xia Q, Pang W, Pan H, et al. (2004): Effects of ghrelin on the proliferation and secretion of splenic $\mathrm{T}$ lymphocytes in mice. Regul Pept 122: 173-178.
49. Chang L, Du JB, Gao LR, et al. (2003): Effect of ghrelin on septic shock in rats. Acta Pharmacol Sin 24: 45-49.

50. Dixit VD, Yang H, Sun Y, et al. (2007): Ghrelin promotes thymopoiesis during aging. J Clin Invest 117: 2778-2790.

51. Tumer C, Bilgin HM, Obay BD, et al. (2007): Effect of ghrelin administration on phagocytic activity in acute coldrestraint stress exposed rats. Regul Pept 138: 113-117.

52. Pulkkinen L, Ukkola O, Kolehmainen M, et al. (2010): Ghrelin in diabetes and metabolic syndrome. Int J Pept 4. doi: $10.1155 / 2010 / 248948$.

53. Aydin S (2007): A comparison of ghrelin, glucose, alpha-amylase and protein levels in saliva from diabetics. J Biochem Molec Biol 40: 29-35.

54. Mohamed HG, Idris SB, Mustafa M, et al. (2015): Impact of chronic periodontitis on levels of glucoregulatory biomarkers in gingival crevicular fluid of adults with and without Type 2 diabetes. PLoS One 10: e0127660.

55. Yilmaz G, Kirzioglu FY, Doguc DK, et al. (2014): Ghrelin levels in chronic periodontitis patients. Odontology 102: 59-67.

56. Karmiris K, Koutroubakis IE, Kouroumalis EA (2008): Leptin, adiponectin, resistin, and ghrelin implications for inflammatory bowel disease. Mol Nutr Food Res 52: 855-866.

57. Wang L, Chen Q, Li G, et al. (2012): Ghrelin stimulates angiogenesis via GHSR1a-dependent MEK/ERK and PI3K/Akt signal pathways in rat cardiac microvascular endothelial cells. Peptides 33: 92-100.

58. Baiquera S, Conconi MT, Guidolin D, et al (2004): Ghrelin inhibits in vitro angiogenic activity of rat brain microvascular endothelial cells. Int J Mol Med 14: 849-854.

59. Ahluwalia A, Li A, Cheng G, et al. (2009): Reduced ghrelin in endothelial cells plays important mechanistic role in aging-related impairment of angiogenesis. J Physiol Pharmacol 60: 29-34.

60. Booth V, Young S, Cruchley A, et al. (1998): Vascular endothelial growth factor in human periodontal disease. J Periodont Res 33: 491-499.

61. Chapple CC, Kumar RK, Hunter N (2000): Vascular remodeling in chronic inflammatory periodontal disease. J Oral Pathol Med 29: 500-506.

62. Yagi T, Ueda H, Amitani H, et al. (2012): The Role of ghrelin, salivary secretions, and dental care in eating disorders. Nutrients 4: 967-989.

63. Robb ND, Smith BG (1996): Anorexia and bulimia nervosa (the eating disorders): conditions of interest to the dental practitioner. J Dent 24: 7-16.

64. De Bate RD, Tedesco LA, Kerschbaum WE (2005): Knowledge of oral and physical manifestations of anorexia and bulimia nervosa among dentists and dental hygienists. J Dent Educ 69: 346-354.

65. Montecchi PP, Custureri V, Polimeni A, et al. (2003): Oral manifestations in a group of young patients with anorexia nervosa. Eat Weight Disord 8: 164-167.

66. Studen-Pavlovich D, Elliott MA (2001): Eating disorders in women's oral health. Dent Clin N Am 45: 491-511.

67. Wentz E, Mellstrom D, Gillberg IC, et al. (2007): Brief report: decreased bone mineral density as a long-term complication of teenage-onset anorexia nervosa. Eur Eat Disord Rev 15: 290-295.

68. Do Carmo I, Mascarenhas M, Macedo A, et al. (2007): A study of bone density change in patients with anorexia nervosa. Eur Eat Disord Rev 15: 457-462. 
69. Shaughnessy BF, Feldman HA, Cleveland R, et al. (2008): Oral health and bone density in adolescents and young women with anorexia nervosa. J Clin Pediatr Dent 33: 87-92.

70. Schwartz MW, Woods SC, Porte D Jr, et al. (2000): Central nervous system control of food intake. Nature 404: 661-671.

71. Seoane LM, Lopez M, Tovar S, et al. (2003): Agouti-related peptide, neuropeptide $\mathrm{Y}$, and somatostatin -producing neurons are targets for ghrelin actions in the rat hypothalamus. Endocrinology 144: 544-551.

72. Andrews ZB, Liu ZW, Wallingford N, et al. (2008): UCP2 mediates ghrelin's action on NPY/AgRP neurons by lowering free radicals. Nature 454: 846-851.

73. Banks WA, Tschop M, Robinson SM, et al. (2002): Extent and direction of ghrelin transport across the blood-brain barrier is determined by its unique primary structure. J Pharmacol Exp Ther 302: 822-827.

74. Proctor GB, Carpenter GH (2007): Regulation of salivary gland function by autonomic nerves. Auton Neurosci 133: 3-18.

75. Ohta K, Laborde NJ, Kajiya M, et al. (2011): Expression and possible immune-regulatory function of ghrelin in oral epithelium. J Dent Res 90: 1286-1292.

76. Eres G, Demitras CSA, Toptas E, et al. (2019): Correlations between the peptide hormone ghrelin and Proinflammatory cytokines in experimental periodontitis models of female rats at different stages of the life cycle. Arch Oral Biol 108: 104518.

77. Nokhbehsaim M, Damanaki A, Nogueira AVB, et al. (2017): Regulation of ghrelin receptor by periodontal bacteria in vitro and in vivo. Mediators Inflamm 2017: 4916971.

78. Nokhbehsaim M, Nogueira AVB, Memmert S, et al. (2019): Regulation of ghrelin receptor by microbial and inflammatory signals in human osteoblasts. Braz Oral Res 33: e25.

79. Nokhbehsaim M, Memmert S, Damanaki A, et al. (2019): Effect of interleukin-1 beta on ghrelin receptor in periodontal cells. Clin Oral Investig 23: 113-122.

80. Kanamoto N, Akamizu T, Hosoda H, et al (2002): Substantial production of ghrelin by a human medullary thyroid carcinoma cell line. J Clin Endocrinol Metab 86: 4984-4990.

81. Volante M, Allia E, Gugliotta I, et al. (2002): Expression of ghrelin and GHS receptor by pancreatic islet cells and related endocrine tumors. J Clin Endocrinol Metab 87: 1300-1308.

82. Jeffery PL, Herington AC, Chopin LK (2003): The potential autocrine/paracrine rules of ghrelin and its receptor in hormone-dependent cancer. Cytokine Growth Factor Rev 14: 113-122.

83. Cassoni P, Papotti M, Ghe C, et al. (2001): Identification, characterization, and biological activity of specific receptors for natural ghrelin and synthetic growth hormone secretagogues and analogs in human breast carcinomas and cell lines. J Clin Endocrinol Metab 86: 1738-1745.

84. Jeffery PL, Herington AC, Chopin LK (2002): Expression and action of the growth hormone releasing peptide ghrelin and its receptor in prostate cancer cell lines. J Endocrinol 171: 7.

85. Tsung CL, Hsiao M (2017): Ghrelin and cancer progression. Biochim Biophys Acta Rev Cancer 1868: 51-57.

86. Chopin L, Walpole C, Seim I, et al. (2011): Ghrelin and cancer. Mol Cell Endocrinol 340: 65-69.

87. Alnema MM, Aydin S, Ozkan Y, et al. (2010): Ghrelin and obestatin expression in oral squamous cell carcinoma: an immunohistochemical and biochemical study. Mol Cell Biochem 339: 173-179.
88. Lou J, Liu L, Zhang W, et al. (2019): Differential expression of ghrelin and GHSR via the Mtor pathway during the dynamic carcinogenic process involving oral, potentially malignant disorders. Biosci Rep 39: BSR20192102.

89. Nikolopoulos D, Theocharis S, Kouraklis G (2010): Ghrelin: a potential therapeutic target for cancer. Regul Pept 163: 7-17.

90. Collden G, Tschop MH, Muller TD (2017): Therapeutic potential of targeting the ghrelin pathway. Int J Mol Sci 18: $1-29$. 